Bir Üniversite Hastanesinde Pediatrik ve Yenidoğan Yoğun Bakım Ünitelerinde Sağlık Bakımı İlişkili Enfeksiyonların Kıyaslamalı Değerlendirilmesi: Yedi Yıllık Retrospektif Çalışma

\title{
Comparative Evaluation of Health Care-Related Infections in Pediatric and Newborn Intensive Care Units in A University Hospital: The Seven-Year Retrospective Study
}

\author{
Zeynep Özaslan (0000-0003-2641-4140), Solmaz Çelebi* (0000-0002-3536-0263), \\ Nilgün Köksal $^{\star \star}(0000-0002-6067-3886)$, Hilal Özkan** $(0000-0001-5454-5119)$, \\ Gökhan Ocakoğlu*** (0000-0002-1114-6051), Edanur Yeşil* (0000-0002-8926-9959), Arife Özer (0000-0001-9232-0084), \\ Cansu Turan* (0000-0003-3146-6391), Beyhan Bülbül*(0000-0002-5720-1212), \\ Mustafa Hacımustafaoğlu*(0000-0003-4646-660X) \\ Uludağ Üniversitesi Tıp Fakültesi, Çocuk Sağlığı ve Hastalıkları Anabilim Dalı Bursa, Türkiye \\ *Uludağ Üniversitesi Tıp Fakültesi, Çocuk Sağlığı ve Hastalıkları Anabilim Dalı, Çocuk Enfeksiyon Bilim Dalı, Bursa, Türkiye \\ **Uludağ Üniversitesi Tıp Fakültesi, Çocuk Sağlığı ve Hastalıkları Anabilim Dalı, Neonotoloji Bilim Dalı, Bursa, Türkiye

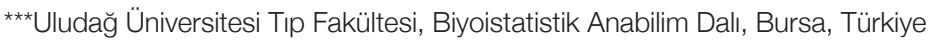

\section{Anahtar kelimeler}

Sağlık bakımı ilişkili enfeksiyon, çocuk yoğun bakım ünitesi, yenidoğan yoğun bakım ünitesi

\section{Keywords}

Healthcare associated infection, pediatric intensive care unit, neonatal intensive care unit

Geliş Tarihi/Received : 22.02.2021

Kabul Tarihi/Accepted : 07.05.2021

DOI:10.4274/jcp.2021.0029

Yazışma Adresi/Address for Correspondence: Dr. Mustafa Hacımustafaoğlu, Uludağ Üniversitesi Tıp Fakültesi, Çocuk Sağlığı ve Hastalıkları Anabilim Dalı, Çocuk Enfeksiyon Bilim Dalı, Bursa, Türkiye

E-posta: mkemal@uludag.edu.tr
$\ddot{O} \mathbf{z}$

Giriş: Bu çalışmada Bursa Uludağ Üniversitesi Tıp Fakültesi Hastanesi'nde Çocuk Yoğun Bakım Ünitesinde (ÇYBÜ) ve Yenidoğan Yoğun Bakım Ửnitesinde (YDYBÜ) saptanan Sağlık Bakımı İlişkili Enfeksiyonların (SBİE) insidansı, dansitesi ve karşılıklı ilişkilerinin genel bir durum tespiti çerçevesinde değerlendirilmesi amaçlandı.

Gereç ve Yöntem: Bu çalışmada Hastalık Kontrol ve Korunma Merkezleri (CDC) 2015 ve Ulusal Hastane Enfeksiyonları Sürveyans Ağı (UHESA) 2017 kriterleri dikkate alınarak 2012 - 2018 yılları arasında SBİE gelişen 91 ÇYBÜ hastası ve 158 YDYBÜ hastasının verileri retrospektif olarak incelendi.

Bulgular: ÇYBÜ ve YDYBÜ de sırasıyla; SBİE hızı, ÇYBÜ’ye göre YDYBÜ'de daha yüksek (\%9,6'ya karş1 \%14,9; p<0,001) ancak SBİE dansitesi ise daha düşük (9,9/1000 hasta gününe karşı 7,8/1000 HG; p=0,061) saptandı. Tüm hastaların yatış günü; YDYBÜ'de daha uzun (sırasıyla 9,7 güne karşı 19,1 gün; $p<0,001$ ) saptanırken SBİE tanısı alan hastaların medyan yatış süreleri ÇYBÜ ve YDYBÜ için sırasıyla (49 güne karşı 41,5 gün; $p=0,1$ ), SBİE tanı alma günlerinin medyanı sırasıyla (17 güne karşı 15 gün; $\mathrm{p}=0,6)$ saptand1. YDYBÜ'de doğum ağırlığına göre SBİE hızları ve dansiteleri sirası ile $\leq 750$ gr hastalarda $\% 7,8$ ve 2,75/1000 HG; 750-1000 gr hastalarda $\% 23,2$ ve 6,2/1000 HG, 1001-1500 gr hastalarda $\% 6,1$ ve 4,98 HG, 1501-2500 gr hastalarda $\% 44,7$ ve 9,2/1000 HG; $\geq 2501$ gr hastalarda $\% 24,6$ ve $13,8 / 1000$ HG olduğu bulundu. $\geq 1501$ gr olan bebeklerde SBİE oranları daha yüksek saptandı.

Sonuç: ÇYBÜ ve YDYBÜ'de SBİE oranlarında ve önleme stratejilerinde farklılıklar olabileceği ve enfeksiyon kontrol önlemleri için sürekli ve kaliteli biçimde idamesi önemlidir. 


\begin{abstract}
Introduction: In this study, it was aimed to evaluate the incidence, density and reciprocal relationships of Health Care Associated Infections (HCAIs) detected in the Pediatric Intensive Care Unit (PICU) and Neonatal Intensive Care Unit (NICU) in Bursa Uludag University Faculty of Medicine Hospital as a general perspective.

Materials and Methods: In this study, data of 91 PICU and 158 NICU patients who developed HCAIs between 2012-2018 years, taking into account the criteria of the Centers for Disease Control and Prevention (CDC) 2015 and the Turkish National Hospital Infections Surveillance Network (UHESA) 2017, were retrospectively analyzed.

Results: The HCAIs rate was higher in NICU (9.6\% vs $14.9 \%$; respectively, p <0.001), but the infection density was lower (9.9 versus 7.8/1000 patient days, $\mathrm{p}=0.061$ ). Stay of length for all patients in NICU was found to be longer (19.1 days vs 9.7 days; $\mathrm{p}$ $<0.001$ ), and the median length of stay with HCAIs in PICU and in NICU was 41.5 days versus 49 days respectively ( $\mathrm{p}=0.1$ ). The median time of HCAIs diagnosis was 17 days in PICU vs 15 days in NICU, p=0.6). In NICU, according to birth weight, HCAIs rates and infection densities were $7.8 \%$ and 2.7/1000 patient-days in $<750$ g patients; $23.2 \%$ and $6.2 / 1000$ patient-days in $751-1000$ $\mathrm{g}$ patients, $6.1 \%$ and 4.9 patient-days in 1001-1500 g patients, $44.7 \%$ and 9.2/1000 patient-days in 1501-2500 g patients, and $\% 24.6$ and 13.8/1000 patient-days in $>2501 \mathrm{~g}$ patients. HCAIs rates were found to be higher in babies with $>1501 \mathrm{~g}$.

Conclusions: There may be differences in the rates and prevention strategies in PICU and NICU and continuous and high quality maintenance is important for infection control measures.
\end{abstract}

\section{Giriş}

Sağlık Bakımı İlişkili Enfeksiyon (SBİE), gelişmiş ve gelişmekte olan ülkelerde sağlık hizmet kalitesinin önemli bir göstergesidir. Yoğun bakım üniteleri (YBÜ) risk faktörleri fazla olan hastaların tedavi edilmesi sebebi ile SBİE'nin en sık görüldüğü kliniklerdir. Dünyadaki çalışmalarda Çocuk Yoğun Bakım Ünitelerinde (ÇYBÜ) SBİE hızı \%3,6-\%20 arasında (1-8), Yenidoğan Yoğun Bakım Ünitelerinde (YDYBÜ) ise SBİE hızı \%7,3 ile \%57,7 arasında bildirilmiştir (2,9-17). Türkiye'de ÇYBÜ'de SBİE hızları \%2,9 ile \%43,9 arasinda (18-26) ve YDYBÜ'lerde yapılan çalışmalarda ise \%3,2 ile \%42,3 arasında $(23,27-$ 33) bildirilmiştir. Ancak Türkiye'de ÇYBÜ ve YDYBÜ'de SBİE'lerin birlikte değerlendirildiği çalışmaya rastlanılmamıştır. Bu çalışmada 7 yıllık sürede kliniğimizde ÇYBÜ ve YDYBÜ'de saptanan SBİE insidansı, enfeksiyon dansitesi ve karşılıklı ilişkilerinin genel bir durum tespiti çerçevesinde değerlendirilmesi amaçlandı.

\section{Gereç ve Yöntem}

$\mathrm{Bu}$ çalışmada Amerikan Hastalık Kontrol ve Korunma Merkezi (The Centers for Disease Control and Prevention: CDC) 2015 (34) ve (Ulusal Hastane Enfeksiyon Sürveyans Ağı) UHESA 2017 kriterleri (35) dikkate alınarak 2012 - 2018 yılları arasında SBİE gelişen 91 ÇYBÜ hastası ve 158 YDYBÜ hastasının verileri retrospektif olarak incelendi. Yedi yıllık bir sürede (2012 - 2018 yılları arasında) Çocuk Enfeksiyon Hastalıkları Bilim Dalı elektronik dosya verileri incelenerek, SBİE gelişen ÇYBÜ ve YDYBÜ hastaları çıkarıldı ve tek tek değerlendirildi. Olguların yaş, cinsiyet, primer tanı, yatış süresi, SBİE tanısı konma günleri ve karşılıklı olarak kıyaslanmaları yapıld1. Kullanılan oranlardan; servis Yatak doluluk orant $=($ yatılan toplam gün sayıs1 $\mathrm{x} 100) /(365 \mathrm{x}$ hasta yatak sayısı) formülüne göre hesapland1. Doluluk oranının \%100'den fazla olması hasta yoğunluğunun çok olduğu dönemlerde yoğun bakıma resmi kapasiteye ek olarak ekstra yatak ilave edilmesinden kaynaklandi. SBIE hlzl=(SBİE sayıs1 / yatan hasta sayis1) x 100 formülüne göre ve SBIE dansitesi=(SBIE say1s1 / hasta yatış günü; HG) x 1000 formülüne göre hesaplandı. YDYBÜ de doğum tartısına göre ( $\leq 750 \mathrm{gr}, 750-1000$ gr, 1001-1500 gr 1501-2500 gr ve $\geq 2501$ gr) ayrica değerlendirme yapıldı. Sürekli değişkenlerin normal dağılıma uygunluğu Kolmogorov Smirnov testi ile incelendi.Sürekli değişkenlernormaldağılımauygunluk testi sonucuna göre medyan (minimum-maksimum), ortalama \pm standart sapma değerleriyle ifade edildi. Kategorik değişkenler ise $\mathrm{n} / \mathrm{N}(\%)$ değerleriyle ile ifade edildi. Sürekli değişkenlerin gruplar arasında yapılan karşılaştırmalarında Kruskal Wallis ve Mann Whitney U testi; kategorik değişkenlerin gruplar arasında yürütülen karşılaştırmalarında ise ki-kare, Fisher'in kesin ki-kare ya da Fisher-Freeman-Halton testleri kullanıldı. İstatistiksel analizler için SPSS (IBM Corp. Released 2012. IBM SPSS Statistics for Windows, Version 21,0 Armonk, NY: IBM Corp.) programı kullanıldı. Anlamlılık $\mathrm{p}<0,05$ düzeyinde değerlendirildi ve çalışmada gerçek p değerleri kullanıldı. 


\section{Bulgular}

UÜTF ÇSH Anabilim Dalı toplam 126 yatak kapasiteli olup (ÇYBÜ 10 yatak kapasiteli, YDYBÜ 2012-2015 yılları arasinda 15, 2016-2018 yılları arasında 16 yatak kapasiteli) çalışma süresi boyunca (01/01/2012-31/12/2018 tarihleri arasında) ÇYBÜ'de takip edilen hasta sayısı 2851, YDYBÜ'de takip edilen hasta sayıs1 ise 2110 idi.

ÇYBÜ'de yatan ve SBİE gelişen toplam 91 hasta değerlendirmeye alındı ve hasta başına ortalama 3 (275/91) anlamlı üreme oldu. YDYBÜ'de SBİE gelişen 158 hasta değerlendirmeye alındı ve hasta başına ortalama $2(315 / 158)$ anlamlı üreme oldu.

ÇYBÜ ve YDYBÜ'de SBİE gelişen olguların demografik, yatış özellikleri ve eşlik eden hastalıkları Tablo 1, 2 ve 3 'te görülmektedir.
ÇYBÜ ve YDYBÜ'de yatan hastaların SBIE verileri kıyaslamalı olarak Tablo 4'te özetlendi.

ÇYBÜ’ye kıyasla YDYBÜ'de daha uzun $(9,7$ güne karşı 19,1 gün; $p<0,001)$, SBİE hızı daha yüksek (9,6'ya karş1 14,9; p<0,001) ancak SBİE dansitesi ise daha düşük $(9,9 / 1000$ HG'ye karşı 7,8/1000 HG; 0,061 ) bulundu.

YDYBÜ'de yatan hastalarda doğum ağırlığına göre SBİE hız, dansite verileri ise Tablo 5 'te özetlendi. $\geq 1501$ gr olan bebeklerde SBİE oranları daha yüksek saptand. YDYBÜ'de yatan hastalarda doğum ağırlığına göre verileri incelendiğinde tüm hastaların \%31'i $\geq 1501$ gr olmasina rağmen, tüm SBİE'lerin \%70,6'sını $\geq 1501$ gr olan bebeklerin oluşturduğu görüldü (Tablo 5).

Tablo 1. ÇYBÜ ve YDYBÜ'deki SBİE tanılı hastaların demografik özellikleri

\begin{tabular}{|c|c|c|c|}
\hline Demografik özellikler & $\begin{array}{l}\text { ÇYBÜ } \\
n=91\end{array}$ & $\begin{array}{l}\text { YDYBÜ } \\
n=158\end{array}$ & $\mathrm{p}$ \\
\hline Yaş (gün) & $\begin{array}{l}24(1-212) \text { ay } \\
63 \pm 75\end{array}$ & $\begin{array}{l}1(1-23) \text { gün } \\
2,4 \pm 4,1\end{array}$ & \\
\hline \multicolumn{4}{|l|}{ Cinsiyet } \\
\hline $\mathrm{K} 1 \mathrm{Z}$ & $39 / 91(\% 42,9)$ & $73 / 158(\% 46,2)$ & 0,621 \\
\hline Erkek & $52 / 91(\% 57,1)$ & $85 / 158(\% 53,8)$ & \\
\hline \multicolumn{4}{|l|}{ Primer tanı } \\
\hline Nörolojik hastalık & $28 / 91(\% 31)$ & $12 / 158(\% 7,6)$ & $<0,001$ \\
\hline Hematojen ve solid organ malignansı & $18 / 91(\% 19,7)$ & $2 / 158(\% 1,3)$ & $<0,001$ \\
\hline Kalp hastalığ & $16 / 91(\% 18)$ & $21 / 158(\% 13,3)$ & 0,32 \\
\hline Metabolik hastalık & $12 / 91(\% 13)$ & $7 / 158(\% 4,4)$ & 0,012 \\
\hline Akciğer hastalığ & $4 / 91(\% 4)$ & $2 / 158(\% 1,3)$ & 0,82 \\
\hline Gastrointestinal hastalık & $4 / 91(\% 4)$ & $5 / 158(\% 3,2)$ & 0,78 \\
\hline Konjenital anomali & $4 / 91(\% 4)$ & $7 / 158(\% 4,4)$ & $>0,9$ \\
\hline Hipoksik iskemik ensefalopati & $3 / 91(\% 3)$ & $7 / 158(\% 4,4)$ & 0,76 \\
\hline Renal hastalık & $1 / 91(\% 1)$ & $4 / 158(\% 2,5)$ & 0,67 \\
\hline Prematürite komplikasyonları & $1 / 91(\% 1)$ & - & - \\
\hline Prematurite & - & $73 / 158(\% 46,2)$ & - \\
\hline Genetik hastalık & - & $2 / 158(\% 1,3)$ & - \\
\hline Dermatolojik hastalık & - & $4 / 158(\% 2,5)$ & - \\
\hline Endokrin hastalık & - & $1 / 158(\% 0,6)$ & - \\
\hline Ürogenital hastalık & - & $4 / 158(\% 2,5)$ & - \\
\hline Hiperbilüribinemi & - & $7 / 158(\% 4,4)$ & - \\
\hline TOPLAM & $91 / 91(\% 100)$ & $158 / 158(\% 100)$ & \\
\hline
\end{tabular}




\section{Tartışma}

Dünya Sağlık Örgütü (DSÖ)'nün SBİE'leri önlemeye yönelik 2002 senesinde yayınladı̆̆1 bildirgede; Avrupa, Doğu Akdeniz, Güneydoğu Asya ve Batı Pasifik'te 55 hastaneyi kapsayan bir çalışmada, hastanede yatan çocuk ve erişkin hastaların \%8,7'sinde SBİE geliştiği bildirilmiştir (36). ABD'de 2011 senesinde, 11,000'den fazla rastgele seçilen çocuk hasta üzerinde SBİE yönelik yapılan bir çalışmada, tüm yatan çocuk hastaların \%4'ünde SBİE tespit edilmiştir (37). Aynı çalışmanın devamında ABD'de, 2015 senesinde, 10 farklı eyalette, farklı büyüklükte 199 genel veya çocuk hastanelerinde hizmet almış, rastgele seçilen herhangi bir yaştaki 12,299 hasta üzerinde SBİE'lere yönelik bir nokta prevelans çalışmasında SBİE hızının \%3,28 tespit edildiği bildirilmiştir (37). Yukarıdaki veriler genel hastane verileridir. Çocuklarda YBÜ'de yatan hastaların kritik özellikli hastalar olması nedeniyle YBÜ'lerde SBİE hızları daha yüksek olup ayrı bir önem arzeder. Ayrıca SBİE ile ilgili yapılan çalışmaların kıyaslamalı değerlendirilmesinde; hangi tanı kriterlerine göre SBİE tanısı konulduğu da çok önemlidir. Tanı kriterlerinin de CDC 2015 veya ülkemizde UHESA 2017 kriterlerinin konulduğu tarihten önceki çalışmaların kriterlerininörneğin klinik sepsis kriterleri kaldırılmıştır- farklı

Tablo 2. ÇYBÜ ve YDYBÜ’deki SBİE tanılı hastaların yatış özellikleri

\begin{tabular}{|c|c|c|c|c|c|}
\hline \multicolumn{2}{|l|}{ Yatış özellikleri } & \multicolumn{2}{|c|}{$\begin{array}{l}\text { ÇYBÜ } \\
n=91\end{array}$} & $\begin{array}{l}\text { YDYBÜ } \\
\mathrm{n}=158\end{array}$ & $\mathrm{p}$ \\
\hline \multicolumn{6}{|l|}{ YBÜ'ye nereden yattığ1 } \\
\hline Acil servis & & \multicolumn{2}{|c|}{$63 / 91(\% 69,2)$} & $11 / 158(\% 7)$ & $<0,001$ \\
\hline Dış merkezden sevk & & \multicolumn{2}{|c|}{$10 / 91(\% 10,9)$} & $27 / 158(\% 17,1)$ & 0,193 \\
\hline Kendi kliniklerimizden & & \multicolumn{2}{|c|}{$8 / 91(\% 8,8)$} & - & - \\
\hline YDYBÜ'den devir & & \multicolumn{2}{|c|}{$7 / 91(\% 7,7)$} & - & - \\
\hline Kalp damar YBÜ'den devir & & \multicolumn{2}{|c|}{$3 / 91(\% 3,3)$} & $9 / 158(\% 5,7)$ & 0,544 \\
\hline Merkezimizde doğum & & \multicolumn{2}{|l|}{-} & $111 / 158(\% 70,2)$ & - \\
\hline Toplam yatış süresi (gün) & & \multicolumn{2}{|c|}{$\begin{array}{l}49(6-316) \\
77 \pm 72\end{array}$} & $\begin{array}{l}41,5(4-196) \\
54,2 \pm 40,5\end{array}$ & 0,132 \\
\hline \multicolumn{2}{|l|}{ SBİE tanı alma günü } & \multicolumn{2}{|c|}{$\begin{array}{l}17(3-175) \\
28,4 \pm 33,9\end{array}$} & $\begin{array}{l}15(3-120) \\
23,5 \pm 24,7\end{array}$ & 0,621 \\
\hline \multicolumn{2}{|l|}{ Taburcu } & \multicolumn{2}{|c|}{$52 / 91(\% 57,1)$} & $103 / 158(\% 65,2)$ & \multirow{3}{*}{$\begin{array}{l}0,207 \\
0,053\end{array}$} \\
\hline Sevk ya da devir & & & $65,5)$ & $21 / 158(\% 13,3)$ & \\
\hline TOPLAM & & & $\% 100)$ & $158 / 158(\% 100)$ & \\
\hline \multicolumn{6}{|c|}{$\begin{array}{l}\text { ÇYBÜ: çocuk yoğun bakım ünitesi, YDYBÜ: yenidoğan yoğun bakım ünitesi, SBİE: sağlık bakımı ilişkili enfeksiyon. Tablodaki tanımlayıcı veriler medyan (minimum- } \\
\text { maksimum), ortalama } \pm \text { standart sapma ve n/N }(\%) \text { olarak verildi }\end{array}$} \\
\hline \multicolumn{6}{|c|}{ Tablo 3. YDYBÜ'de SBİE tanısı alan hastaların doğum ağırlığına göre demografik özellikleri } \\
\hline \multirow{2}{*}{$\begin{array}{l}\text { Hastaların demografik } \\
\text { özellikleri }\end{array}$} & \multicolumn{5}{|c|}{ Doğum A $\breve{g} ı r l ı \breve{g} 1$} \\
\hline & $\begin{array}{l}\leq 750 \\
\operatorname{gr}(n=3)\end{array}$ & $\begin{array}{l}751-1000 \\
\operatorname{gr}(n=22)\end{array}$ & $\begin{array}{l}1001-1500 \mathrm{gr} \\
(\mathrm{n}=30)\end{array}$ & $\begin{array}{l}1501-2500 \mathrm{gr} \\
(\mathrm{n}=31)\end{array}$ & $\begin{array}{l}\geq 2501 \\
\operatorname{gr}(n=72)\end{array}$ \\
\hline \multicolumn{6}{|l|}{ Cinsiyet } \\
\hline Erkek $(\mathrm{n}=85)$ & $2 / 3(\% 66)$ & $11 / 22(\% 50)$ & $17 / 30(\% 57)$ & $11 / 31(\% 35)$ & $44 / 72(\% 61)$ \\
\hline $\mathrm{K} 1 \mathrm{z}(\mathrm{n}=73)$ & $1 / 3(\% 33)$ & $11 / 22(\% 50)$ & $13 / 30(\% 43)$ & $20 / 31(\% 65)$ & $28 / 72(\% 39)$ \\
\hline Toplam yatış günü & $\begin{array}{l}89(55-138) \\
94 \pm 41,7\end{array}$ & $\begin{array}{l}60(4-196) \\
78,3 \pm 49\end{array}$ & $\begin{array}{l}33(6-173) \\
73,5 \pm 40,4\end{array}$ & $\begin{array}{l}69,5(6-173) \\
48,8 \pm 38,8\end{array}$ & $\begin{array}{l}32(4-191) \\
39,3 \pm 30,3\end{array}$ \\
\hline SBİE tanı alma günü & $\begin{array}{l}19(15-75) \\
36,3 \pm 33,3\end{array}$ & $\begin{array}{l}23,5(3-120) \\
38,4 \pm 33,05\end{array}$ & $\begin{array}{l}25(3-110) \\
30 \pm 25,3\end{array}$ & $\begin{array}{l}9(3-111) \\
19,8 \pm 25,2\end{array}$ & $\begin{array}{l}12,5(3-104) \\
17,3 \pm 18,2\end{array}$ \\
\hline
\end{tabular}


olduğu ve bu nedenle SBİE hızlarının bu durum dikkate alınarak değerlendirilmesi gerekmektedir (38).

a. ÇYBÜ'de yatan hastalarda SBIE Hiz ve Dansitesi:

Dünyadaki yapılmış olan ve sadece ÇYBÜ'de yatan hastaların alındığı çalışmalarda SBİE hızları $\% 3,6-\% 20$, SBİE dansiteleri 11,2-24,5/1000 HG arasında bildirilmiştir (1-8) (Tablo 6). Türkiye'deki çalışmalarda ise ÇYBÜ'de yatan hastalarda SBİE hizları \%2,9-\%43,9; SBİE dansiteleri 2,9-21,9/1000 HG arasında $(18,19,21-26)$ bildirilmiştir (Tablo 6).

Bizim çalışmamızda, 2012-2018 yılları arasında ÇYBÜ'de ortalama SBİE hızı \%9,6; SBİE dansitesi 9,9/1000 HG idi. Oranlarımız dünyadaki ve ülkemizdeki yapılan çalışmalarla benzer olmakla birlikte, ülkemizdeki çoğu çalışmaya göre SBİE hızları

Tablo 4. Çocuk Yoğun Bakım Ünitesi ve Yenidoğan Yoğun Bakım Ünitesi’nde yatan tüm hastaların yedi yıllık ortalama yatış süresi, doluluk oranı, SBİE hızı ve SBİE dansitesi verileri

\begin{tabular}{llllllll}
\hline \multirow{2}{*}{ Yatırılan klinik } & $\begin{array}{l}\text { Yatan hasta } \\
\text { sayıs }\end{array}$ & $\begin{array}{l}\text { Yatak } \\
\text { sayıs1 }\end{array}$ & $\begin{array}{l}\text { Hasta } \\
\text { günü }\end{array}$ & $\begin{array}{l}\text { Ortalama yatış } \\
\text { süresi (gün) }\end{array}$ & $\begin{array}{l}\text { Doluluk oranı 1 } \\
(\%)\end{array}$ & $\begin{array}{l}\text { SBİE hız12 } \\
(\%)\end{array}$ & $\begin{array}{l}\text { SBİE dansitesi3 } \\
(/ 1000 \text { hasta günü) }\end{array}$ \\
\hline ÇYBÜ & 2851 & 10 & 27655 & 9,7 & 108,2 & 9,6 & 9,9 \\
YDYBÜ & 2110 & 15,4 & 40395 & 19,1 & 102,4 & 14,9 & 7,8 \\
p & - & - & - & $\mathbf{< 0 , 0 0 1}$ & $0,96<\mathbf{0 , 0 0 1}$ & 0,061 \\
\hline
\end{tabular}

ÇYBÜ: Çocuk Yoğun Bakım Ünitesi YDYBÜ: Yenidoğan Yoğun Bakım Ünitesi SBİE: sağlık bakımı ilişkili enfeksiyon

1:Bir yıllık doluluk oranı; yatak doluluk oranı= (yatılan toplam gün sayısı x 100) / (365 x hasta yatak sayısı) formülüne göre hesaplandı. Doluluk oranının \%100'den fazla olması hasta yoğunluğunun çok olduğu dönemlerde yoğun bakıma resmi kapasiteye ek olarak ekstra yatak ilave edilmesinden kaynaklandı.

2:SBİE hızı; (SBİE sayısı / yatan hasta sayısı) x 100 formülüne göre hesaplandı. Bir hastada birden fazla SBİE gelişebilir.

3:SBİE dansitesi; (SBİE sayısı / HG) x 1000 formülüne göre hesaplandı.

Tablo 5. YDYBÜ’de doğum ağırlığına göre SBİE hız, dansite verileri

\begin{tabular}{|c|c|c|c|c|c|}
\hline Doğum ağırlı̆̆ 1 (gr) & $\begin{array}{l}\text { Toplam hasta sayısı } \\
\text { ve oranı } 1 \\
\mathrm{n} / \mathrm{N}(\%)\end{array}$ & $\begin{array}{l}\text { SBİE tanıs1 alan hasta } \\
\text { sayıs ve oranı } 2 \\
\mathrm{n} / \mathrm{N}(\%)\end{array}$ & $\begin{array}{l}\text { SBİE hızı3 } \\
(\%)\end{array}$ & $\begin{array}{l}\text { Hasta } \\
\text { günü }\end{array}$ & $\begin{array}{l}\text { SBİE dansitesi4 } \\
\text { (/1000 hasta günü) }\end{array}$ \\
\hline$\leq 750$ & $\begin{array}{l}90 / 2110 \\
(\% 4)\end{array}$ & $\begin{array}{l}3 / 158 \\
(\% 1,9)\end{array}$ & $7,77 \mathrm{a}$ & 2539 & $2,75 \mathrm{a}$ \\
\hline $751-1000$ & $\begin{array}{l}227 / 2110 \\
(\% 11)\end{array}$ & $\begin{array}{l}22 / 158 \\
(\% 13,9)\end{array}$ & $23,23 \mathrm{~b}$ & 8501 & $6,23 \mathrm{~b}$ \\
\hline $1001-1500$ & $\begin{array}{l}1143 / 2110 \\
(\% 54)\end{array}$ & $\begin{array}{l}30 / 158 \\
(\% 19)\end{array}$ & $6,12 \mathrm{c}$ & 14061 & $4,98 \mathrm{c}$ \\
\hline $1501-2500$ & $\begin{array}{l}123 / 2110 \\
(\% 6)\end{array}$ & $\begin{array}{l}31 / 158 \\
(\% 19,6)\end{array}$ & $44,71 \mathrm{~d}$ & 5908 & $9,20 \mathrm{~d}$ \\
\hline$\geq 2501$ & $\begin{array}{l}527 / 2110 \\
(\% 25)\end{array}$ & $\begin{array}{l}72 / 158 \\
(\% 45,6)\end{array}$ & $24,66 \mathrm{e}$ & 9386 & $13,85 \mathrm{e}$ \\
\hline $\mathrm{p}$ & & & $\begin{array}{l}<\mathbf{0 , 0 0 1} \\
\text { pa-c :0,53 } \\
\text { pb-e:0,7 } \\
\text { Diğer ikili } \\
\text { karş1laştırmalarda p } \\
<0,001\end{array}$ & & $\begin{array}{l}\mathbf{0 , 0 4} \\
\text { p a-e:0,007 } \\
\text { p c-e:0,03 } \\
\text { diğer ikili } \\
\text { karş1laştırmalarda } \\
\text { p }>0,05\end{array}$ \\
\hline Toplam & $\begin{array}{l}2110 / 2110 \\
(\% 100)\end{array}$ & $\begin{array}{l}158 / 158 \\
(\% 100)\end{array}$ & 14,9 & 40395 & 7,8 \\
\hline
\end{tabular}

YDYBÜ: yenidoğan yoğun bakım ünitesi, SBİE: sağlık bakımı ilişkili enfeksiyon.

1: YDYBÜ'ye yatan toplam hasta sayısı 2110 'dur. Tablodaki oranlar doğum ağırlığına göre hasta sayısının YDYBÜ'de yatan tüm hastalar içindeki oranı ifade eder.

2: YDYBÜ'de yatan SBIE tanısı alan toplam hasta sayısı 158'dir. Tablodaki oranlar doğum ağırlığına göre SBİE tanısı alan hasta sayısının YDYBÜ'deki tüm SBİE tanısı alan hastalar içindeki oranı ifade eder.

3: SBIE hızı; (SBIEE sayısı / doğum ağırlığına göre yatan hasta sayısı) x 100 formülüne göre hesaplandı. Bir hastada birden fazla SBİE gelişebilir.

4: SBİE dansitesi; (SBIEE sayısı / doğum ağırlığında göre HG) x 1000 formülüne göre hesaplandı 
\%7-\%43 ve SBİE dansiteleri 2,8-21,9/ 1000 HG düşük bir seviyede sayılabilir. Ancak kıyaslamalarının sağlıklı olması için, kıyaslanan YBÜ'lerin benzer özellikte olması, yatan hasta niteliği, YBÜ özellikleri gibi ve SBİE aktif sürveyans kalitelerinin benzer standartta olması gerektiği bilinmektedir. Adana'da Celiloğlu ve ark. tarafından yapılan çalışmada (25) saptanan \%2,9'lik düşük SBİE hız ve dansitesi SBİE önleyici tedbirlerin alınması ve retrospektif çalışma olması sebebi ile sürveyans verilerine ulaşılamamış olması olarak belirtilmiştir. Ayrıca Isparta'da Demirok ve ark. tarafindan (26) 2015-2017 yılları arasinda saptanan yüksek SBİE hızı $(\% 43,8)$ klinik olarak SBİE tanısı konulan vakaların fazla olması, yatak doluluk oranının fazla oluşu, uzamış yatış öyküsü, antibiyotik direnci, kateter kullanımının fazla olması ile ilgili olabileceği bildirilmiştir. Daha önce Bursa' da yapılan çalışmalarla kıyaslandığında; çalışmamızda SBİE hızı 2007'deki çalışmaya göre (18) düşük (\%16,3'e karş1 $\% 9,6 ; \mathrm{p}=0,007), 2010-2013$ 'de yapılan çalışmaya göre (23) yüksek bulundu (\%7,4'e karş1 \%9,6; p
$<0,001)$. Çalışmamızda SBİE dansitesi 2007'deki çalışmaya göre (18) düşük (\%18,5'e karş1 \%9,9), 2010-2013'de yapılan çalışmaya göre (23) benzer bulundu (\%9,2'ye karş1 \%9,9). Üçüncü basamak bir ÇYBÜ'sü olan hastanemizde SBİE'ye karşı önlem ve tedbirlerin alınıyor olmasına rağmen, bu süre zarfında komorbiditesi olan karışık hasta popülasyonlarının olması SBİE hızının yüksek olmasına sebep olabilir. Ayrıca belli dönemlerde enfeksiyon kontrol önlemlerindeki gevşeme SBİE hızındaki artışla sonuçlanmış olabilir. Bu nedenle enfeksiyon kontrol önlemlerinin sürekli aynı titizlikle alınması ve düzenli ve kaliteli sürveyansın istiktarlı bir biçimde sürdürülmesi önemlidir.

b. YDYBÜ'de yatan hastalarda SBIE Hiz ve Dansitesi:

Dünyada YDYBÜ'de yatan hastalarda ise SBIE hızlar1 \%7,3-\%57 arasında, SBİE dansitesi 3,229,8/1000 HG olarak bildirilmiştir (2,9-17). Ülkemizde yapılan çalışmalara bakıldığında YDYBÜ'de yatan

\begin{tabular}{|c|c|c|c|c|}
\hline & ÇYBÜ merkezi & $\begin{array}{l}\text { SBİE hızı } \\
(\%)\end{array}$ & $\begin{array}{l}\text { SBİE dansitesi } \\
(/ 1000 \mathrm{HG})\end{array}$ & Referans \\
\hline \multirow[t]{8}{*}{ Dünya } & Litvanya (çok merkez, 2003-2005) & $\% 13,6$ & $24,5 / 1000$ & (1) \\
\hline & Estonya(tek merkez, 2004-2008) & $\% 9,2$ & $12,8 / 1000$ & $(2)$ \\
\hline & Peru (tek merkez, 2006-2007) & $\% 19,5$ & - & (3) \\
\hline & El Salvador(tek merkez 2007-2009) & $\% 15,5$ & - & (4) \\
\hline & Hindistan (tek merkez,2014-2016) & $\% 20$ & - & (5) \\
\hline & Japonya (tek merkez, 2013) & $\% 6,6$ & $11,2 / 1000$ & $(6)$ \\
\hline & İtalya Brezilya (çok merkez, 2010-2014 ) & $\% 3,6$ & - & (7) \\
\hline & Misır (tek merkez,2014-2015) & $\% 15,6$ & - & $(8)$ \\
\hline \multirow[t]{10}{*}{ Türkiye } & UÜTF (tek merkez 2007) & $\% 16,3$ & $18,5 / 1000$ & $(18)$ \\
\hline & Marmara (tek merkez 2008-2010) & $\% 16,5$ & - & $(20)$ \\
\hline & İzmir (tekmerkez, 2010) & $\% 32,1$ & - & $(21)$ \\
\hline & Kayseri (tek merkez,2008) & $\% 21,1$ & - & $(22)$ \\
\hline & UÜTF (tek merkez, 2010-2013) & $\% 7,40$ & $9,2 / 1000$ & $(23)$ \\
\hline & Marmara (tek merkez 2011-2013) & $\% 22,24$ & $20,7 / 1000$ & $(24)$ \\
\hline & Adana (tek merkez, 2012-2016) & $\% 2,9$ & $2,89 / 1000$ & $(25)$ \\
\hline & Isparta (tek merkez, 2010-2011) & $\% 33,30$ & $11,2 / 1000$ & (26) \\
\hline & Isparta (tek merkez, 2012-2013) & $\% 13,27$ & $19,2 / 1000$ & (26) \\
\hline & Isparta (tek merkez, 2015-2017) & $\% 43,88$ & $21,9 / 1000$ & (26) \\
\hline \multicolumn{2}{|c|}{ Çalışmamız (2012-2018) } & $\% 9,6$ & $9,9 / 1000$ & \\
\hline
\end{tabular}


hastalarda SBİE hızları \%3,2-\%42,3 arasında, SBİE dansitelerinin 3,1-21,3/1000 HG olduğu bildirilmiştir $(23,28-31,33)$ (Tablo 7).

Bizim çalışmamızda, YDYBÜ'de yatan hastalardaki SBIE hızı $(\% 14,9)$, dünya (\%7,357,3) ve Türkiye'deki (\%3,1-21,3) SBİE hızlarına benzerdi. Çalışmamızda SBİE dansitesi de (7,8/1000 HG) dünya $(3,2-29,8 / 1000 \mathrm{HG})$ ve Türkiye $(3,1-$ 21,3/1000 HG) verilerine benzerdi. Ancak dünya ve Türkiye'deki oranların çok geniş bir dağılım gösterdiği dikkate alınmalıdır. Değişik YDYBÜ'de yatan hasta özellikleri (ÇDDA, premature, üçüncü düzey ve komplike hastaların yatışı gibi) SBİE sıklığı ile yakından ilişkilidir. Bu nedenle sağlıklı kıyaslama için benzer özellikteki YDYBÜ'lerin seçilmesi gerektiği unutulmamalıdır. Brezilya'daki (9) \%57'lik yüksek SBİE hızı yaygın antimikrobiyal kullanımı bunun sonucunda dirençli suşların oluşumu, hasta bakım uygulamaları, yoğun bakımlar için ayırılan sınırlı mali kaynak ile ilişkili olabileceği belirtilmiştir. Mısır'daki $(13,14) \% 21,4$ ve \%38,5'lik yüksek SBİE hızı, düşük doğum ağırlığı ile SBİE hızının ters orantılı oluşu, çalışma kaynaklarının farklılığı, surveyans yöntemlerindeki farklılıklara bağlı olabileceği belirtilmiştir. Ayrıca yine Bursa'da yapılan 2007'deki \%42'lik (132/314) (18) ve 2010-2013'deki \%28'lik (310/1108) (23) SBİE hızları saptanan çalışmalara bakıldığında; YDYBÜ SBİE hızının merkezimizde yapılan iki çalışmaya göre de anlamlı olarak azaldığı tespit edildi (surasiyla $p<0,001$ ve $p<0,001$ ). SBIEE dansitelerine bakıldı ğında ise 2007'de 14/1000 HG (18) ve 2010-2013'deki 15,8/1000 HG (23) olup çalışmamızda SBİE dansitesinin $(7,8 / 1000$ HG) düşük olduğu saptandı. Hastanemizde ÇSH

\begin{tabular}{|c|c|c|c|c|}
\hline & YDYBÜ merkezi & SBİE hızı & SBİE dansitesi & Referans \\
\hline \multirow[t]{14}{*}{ Dünya } & Brezilya (çok merkez, 1993-2002) & $\% 57,7$ & $29,8 / 1000$ & (9) \\
\hline & İtalya (çok merkez, 2006-2010) & $\% 15$ & $6,9 / 1000$ & $(10)$ \\
\hline & ÇDDA $(\leq 1500$ gr doğan $)$ & & $8,8 / 1000$ & \\
\hline & $\geq 1501$ gr doğan & & $5,1 / 1000$ & \\
\hline & Polonya (tek merkez, 2005-2010) & $\% 4,1-11,8(7,3)$ & - & $(11)$ \\
\hline & Japonya (ÇDDA) (tek merkez, 2005-2009) & $\% 15,2$ & - & $(12)$ \\
\hline & El Salvador (tek merkez, 2007-2009) & $\% 23,8$ & $9,8 / 1000$ & (4) \\
\hline & Misır (tek merkez, 2009-2010) & $\% 21,4$ & $13,8 / 1000$ & (13) \\
\hline & Misır (tek merkez, 2012-2013) & $\% 38,5$ & - & \\
\hline & $<27$ hafta & $\% 93,7$ & & $(14)$ \\
\hline & ADDA $(\leq 1000$ gr $)$ & $\% 62$ & & \\
\hline & ÇDDA ( $\leq 1500$ gr) & $\% 43$ & & \\
\hline & İran (çok merkez, 2012-2013) & $\% 11,3$ & - & $(15)$ \\
\hline & İtalya (tek merkez 2013-2017) & $\% 9,9$ & $3,2 / 1000$ & $(17)$ \\
\hline \multirow[t]{8}{*}{ Türkiye } & Adana (ÜTF, 2001-2006) & $\% 14-30$ & $11-17 / 1000$ & $(27)$ \\
\hline & Eskişehir (ÜTF, 2005-2006) & $\% 24,4$ & $21,3 / 1000$ & $(28)$ \\
\hline & Uludağ ÜTF (YDYBÜ, 2007) & $\% 42$ & $14 / 1000$ & $(29)$ \\
\hline & Erzurum (devlet hastanesi, 2009-2011) & $\% 3,2$ & $4 / 1000$ & $(30)$ \\
\hline & Ankara ÜTF (ÜTF, 2013) & $\% 11,5$ & $17,04 / 1000$ & $(31)$ \\
\hline & Türkiye (38 merkez nokta prevalans çalışması, 2015 ) & $\% 23,5$ & - & $(32)$ \\
\hline & Uludağ ÜTF (YDYBÜ, 2010-2013) & $\% 28$ & $15,8 / 1000$ & $(23)$ \\
\hline & Sakarya ÜTF (ÜTF, 2012-2017) & $\% 4,78$ & $3,12 / 1000$ & $(33)$ \\
\hline \multicolumn{2}{|c|}{ Çalışmamız (2012-2018) } & $\% 14,9$ & $7,8 / 1000$ & \\
\hline
\end{tabular}

YDYBÜ: yenidoğan yoğun bakım ünitesi, SBİE: sağlık bakımı ilişkili enfeksiyon, ÇDDA: çok düşük doğum ağırlıklı, ADDA: aşırı düşük doğum ağırlıklı, ÜTF: Üniversite Tip Fakültesi 
Enfeksiyon Bilim Dalı'nın ve enfeksiyon kontrol komitesinin SBİE önlemeye yönelik çalışmaları, bu bağlamda sağlık hizmeti veren personellere verilen eğitimlerin, dirençli etkenlerin saptandiğ 1 hastalarda izolasyon uygulamalarının titizlikle yapılmaya çalışılması, girişimsel işlemlerde uygun sterilizasyon ve dezenfeksiyona dikkat edilmesi, saptanan enfeksiyonlarda zamanlı, uygun ve akılcı antibiyotiklerin kullanılması ile merkezimizde SBİE hızının \%14,9'a ve SBİE dansitesinin 7,8/1000 HG'ne kadar azaltılmış olduğu söylenebilir. Ancak önlemlerin istikrarlı bir şekilde ve artarak devam ettirilmesinin gerekliliği de açıktır.

Çalışmamızda ÇYBÜ ve YDYBÜ'deki SBİE hızları kıyaslandığında SBİE hızları YDYBÜ'de daha yüksek $(\% 9,6$ 'ya karş1 \% 14,9; p<0,001) ancak SBİE dansitesi ise daha düşük $(9,9 / 1000$ HG'ye karş1 7,8/1000 HG; p=0,061) saptand1. Özellikle YBÜ'de uzun yatan kritik hastalarda SBİE dansitesinin daha iyi bir gösterge olduğu kabul edildiğinde her iki YBÜ'de SBİE dansitelerinin klyaslanabilir olduğu düşünülebilir. Tüm hastaların yatış günü kıyaslandığında YDYBÜ'de daha uzun (9,7 güne karş1 19,1 gün; $p<0,001)$ saptandı. Bu durum özellikle küçük prematüre bebeklerin daha uzun yatmasıyla ilişkili olabilir. Ortalama yatış süresi $\leq 750$ gr doğan prematürelerde medyan 89 gün iken, $\geq 2501$ gr doğan bebeklerde 32 gün ve ÇYBÜ'de yaklaşık 49 gündü. SBIE tanısı alan hastaların medyan yatış süreleri ÇYBÜ ve YDYBÜ için benzer (49 güne karşı 41,5 gün; $\mathrm{p}=0,1)$ saptand1.

ÇYBÜ ve YDYBÜ'de SBİE tanısı alan hastalar birlikte değerlendirildiğinde; primer tanı olarak nörolojik hastalık (\%31'e karş1 \%7,6), hematojen-solid malignansi (\%19,7'ye karş1 \% 1,3) ve metabolik hastalık $(\% 13$ 'e karş1 \%7,6) ÇYBÜ'de daha fazla, prematürite ve hiperbilüribinemi YDYBÜ'de daha fazla görüldü. Dolayısı ile farklı YBÜ'lerde SBİE tanısı konulurken primer hastalık özellikleri dikkate alınıp bu hastaların yönetimleri sırasında SBİE kontrol önlemlerine özellikle dikkat edilmesi gerekir. Bölgemizde terminal dönem hastaların izlendiği palyatif bakım merkezleri yetersiz olduğundan, özellikle ÇYBÜ'de terminal dönem nörolojik ve hemato-onkolojik hastaların yatırılarak izlenmesi söz konusu olmaktadır. Bu durum hem yatan hasta profilinin değişmesine, hem de uzun süre yatan bu hastaların ÇYBÜ'de SBİE hızlarının biraz daha artmasına yol açabilir. ÇYBÜ'de
SBİE tanısı alan hastaların yatışlarının çoğu (\%69) acil servisten, YDYBÜ'de SBİE tanısı alan hastaların yatışlarının çoğu kadın doğum servisi- doğumhaneden (\%70) yapılmıştı.

Çalışmamızda YDYBÜ'de doğum ağırlığına göre SBİE hızları ve dansiteleri $\leq 750$ gr doğan bebeklerde $\% 7,8$ ve 2,75/1000 HG; 750-1000 gr doğan bebeklerde \%23,2 ve 6,2/1000 HG, 10011500 gr doğan bebeklerde \%6,1 ve 4,98/1000 HG, 1501-2500 gr doğan bebeklerde $\% 44.7$ ve $9.2 / 1000$ HG; $\geq 2501$ gr doğan bebeklerde $\% 24,6$ ve $13,8 / 1000$ HG değişti. YDYBÜ'de $\geq 1501$ gr hastalarda SBİE daha fazla geliştiği saptandı. Bu grup hastalar tüm YDYBÜ hastalarının ortalama \%31'ini (650/2110) oluştururken, SBIE gelişen hastaların \%65'ini (103/158) oluşturdu. Bu grup hastalarda SBİE hızı ve dansitesi $\leq 1500$ gr hastalara kıyasla daha yüksek bulundu (bkz Tablo 5). İtalya'da 2006-2010 yıllarında çok merkezli çalışmada $(10) \leq 1500 \mathrm{gr}$ doğan ÇDDA bebeklerde SBİE dansitesi $\geq 1501$ gr doğan bebeklere göre daha yüksek bulunmuştur. Keza Misır'da 2012-2013 yılında tek merkezde yapılan çalışmada (14), SBİE hızları ÇDDA bebeklerde daha yüksek bulunmuştur. Bu paradoksun sebebi bizim olgularımızda miada yakın bebeklerde eşlik eden ciddi rahatsızlıkların (kardiyak, nörolojik ve metabolik hastalıklar) daha fazla olmasına bağlanabilir.

\section{Sonuç}

İki farkl1 grup pediatrik YBÜ'de (ÇYBÜ ve YDYBÜ) SBİE hızlarında farklılık olabilir. Aynı merkezde bile farklı zamanlarda SBİE oranları anlamlı değişiklik gösterebilir. SBİE'ye zemin oluşturacak farklı risklerin farkında olunmalı ve SBİE önlemleri sürekli ve taviz vermeden uygulanması önemli olacaktır.

\section{Çalışmanın Kısıtlılıkları}

Çalışmanın retrospektif ve tek merkezli bir çalışma olması kısıtlılı̆̆ı olarak düşünülebilir. Diğer çalışmalara kıyasla 7 yıllık bir süreyi kapsaması, düzenli ve ÇSH Enfeksiyon Bilim Dalı kontrolünde sürveyans verilerine dayanması, ÇYBÜ ve YDYBÜ verilerinin birlikte değerlendirilmesi, YDYBÜ'deki hastaların doğum ağırlığına göre SBİE değerlendirmesi yapılması çalışmamızın güçlü yönleri kabul edilebilir. 


\section{Etik}

Çıkar Çatışması: Yazarlar tarafından çıkar çatışması bildirilmemiştir.

Finansal Destek: Yazarlar tarafindan finansal destek almadıkları bildirilmiştir.

\section{Kaynaklar}

1. Asembergiene $\mathrm{J}$, Gurskis V, Kevalas R, Valinteliene R. Nosocomial infections in the pediatric intensive care units in Lithuania. Medicina (Aires) 2009;45:29-36.

2. Mitt P, Metsvaht T, Adamson V, Telling K, Naaber P, Lutsar I, et al. Five-year prospective surveillance of nosocomial bloodstream infections in an Estonian paediatric intensive care unit. J Hosp Infect 2014;86:95-9.

3. Becerra MR, Tantaleán JA, Suárez VJ, Alvarado MC, Candela JL, Urcia FC. Epidemiologic surveillance of nosocomial infections in a Pediatric Intensive Care Unit of a developing country. BMC Pediatr 2010;10:66.

4. Dueñas L, Bran de Casares A, Rosenthal VD, Jesús Machuca L. Device-associated infection rates in pediatric and neonatal intensive care units in El Salvador: Findings of the INICC. J Infect Dev Ctries 2011;5:445-51.

5. Choudhury J, Mohanty D, Routray SS. Microbiological profile of Nosocomial infections in the pediatric patients admitted to intensive care unit. Pediatr Rev Int J Pediatr Res 2016;3:100-4.

6. Hatachi T, Tachibana K, Takeuchi M. Incidences and influences of device-associated healthcare-associated infections in a pediatric intensive care unit in Japan: A retrospective surveillance study. J Intensive Care 2015;3:1-7.

7. Folgori L, Bernaschi P, Piga S, Carletti M, Cunha FP, Lara $\mathrm{PH}$, et al. Healthcare-Associated Infections in Pediatric and Neonatal Intensive Care Units: Impact of Underlying Risk Factors and Antimicrobial Resistance on 30-Day CaseFatality in Italy and Brazil. Infect Control Hosp Epidemiol. 2016;37:1302-9.

8. El-Sahrigy SAF, Shouman MG, Ibrahim HM, Rahman AMOA, Habib SA, Khattab AA, et al. Prevalence and anti-microbial susceptibility of hospital acquired infections in two pediatric intensive care units in Egypt. Open Access Maced J Med Sci 2019;7:1744-9.

9. Couto RC, Carvalho EAA, Pedrosa TMG, Pedroso ÊR, Neto MC, Biscione FM. A 10-year prospective surveillance of nosocomial infections in neonatal intensive care units. Am J Infect Control 2007;35:183-9.

10. Crivaro V, Bogdanović L, Bagattini M, Iula VD, Catania M, Raimondi F, et al. Surveillance of healthcare-associated infections in a neonatal intensive care unit in Italy during 20062010. BMC Infect Dis 2015;15:4-152.

11. Sadowska-Krawczenko I, Jankowska A, Kurylak A. Healthcareassociated infections in a neonatal intensive care unit. Arch Med Sci 2012;8:854-8.

12. Lim WH, Lien R, Huang YC, Chiang MC, Fu RH, Chu SM, et al. Prevalence and pathogen distribution of neonatal sepsis among very-low-birth-weight infants. Pediatr Neonatol 2012;53:228-34.

13. Abdel-Wahab F, Ghoneim M, Khashaba M, El-Gilany AH, Abdel-Hady D. Nosocomial infection surveillance in an Egyptian neonatal intensive care unit. J Hosp Infect 2013;83:196-9.

14. Mohammed D, El Seifi OS. Bacterial nosocomial infections in neonatal intensive care unit, Zagazig University Hospital, Egypt. Egypt Pediatr Assoc Gaz 2014;62:72-9.

15. Hoseini MB, Abdinia B, Rezaee MA, Oskouie SA. The study of nosocomial infections in neonatal intensive care unit: A prospective study in northwest Iran. Int J Pediatr 2014;2:25-33.

16. Auriti C, Ronchetti MP, Pezzotti P, Marrocco G, Quondamcarlo A, Seganti G, et al. Determinants of Nosocomial Infection in 6 Neonatal Intensive Care Units: An Italian Multicenter Prospective Cohort Study. Infect Control Hosp Epidemiol 2010;31:926-33.

17. Scamardo MS, Dolce P, Esposito EP, Raimondi F, Triassi M, Zarrilli R. Trends, risk factors and outcomes of healthcareassociated infections in a neonatal intensive care unit in Italy during 2013-2017. Ital J Pediatr 2020;46:34.

18. Hacımustafaoğlu M, Çelebi S, Tuncer E, Özkaya G, Çak D, Bozdemir E. Çocuk kliniği ve çocuk yoğun bakım ünitesi hastane enfeksiyonları sıklığı. J Pediatr Inf 2009;3:112-7.

19. Şevketoğlu E, Durdu B, Açıkgöz Ö, Leyla G, Bulgur A, Hatipoğlu S. Çocuk yoğun bakım biriminde girişimsel araç ilişkili hastene enfeksiyonları. Türk Pediatr Arşivi 2010;45:13-7.

20. Kuzdan C, Soysal A, Culha G, Altinkanat G, Soyletir G, Bakir M. Three-year study of health care-associated infections in a Turkish pediatric ward. J Infect Dev Ctries 2014;8:1415-20.

21. Anıl AB, Anıl M, Özdemir NÖ, Bayram N, Bal ZŞ, Köse E, et al. Risk factors for hospital-acquired infection in pediatric intensive care unit. J Pediatr Emerg Intens Care Med 2014;1:9-16.

22. Poyrazoğlu H, Dursun İ, Güneș T, Akçakuş M, Konuşkan B, Canpolat M, ve ark. Çocuk yoğun bakım ünitesine yatan olguların değerlendirilmesi ve sonuçları. Erciyes Med J 2008;30:232-7.

23. Yeğin N. Yenidoğan Yoğun Bakım Ünitesi Ve Çocuk Yoğun Bakım Ünitesinde Yatan Hastalarda Sağlık Bakımı İlişkili Enfeksiyonlar: Dört Yıllık Sürveyans Çalışması. 2015;66:37-9. https://acikerisim.uludag.edu.tr/handle/11452/4149

24. Atici S, Soysal A, Kepenekli Kadayifci E, Karaaslan A, Akkoç $\mathrm{G}$, Yakut N, et al. Healthcare-associated infections in a newly opened pediatric intensive care unit in Turkey: Results of fouryear surveillance. J Infect Dev Ctries 2016;10:254-9.

25. Celiloğlu C, Tolunay O, Çelik T, Sucu A, Yurtçu E, Çelik Ü. Çocuk yoğun bakım ünitesindeki hastane enfeksiyonlarının değerlendirilmesi. J Pediatr Infect 2017;11:129-34.

26. Demirok Ö, Çetin H. Süleyman Demirel Üniversitesi T1p Fakültesi, Çocuk Yoğun Bakım Servisi Hastane Enfeksiyonları Sürveyans1 : İki Yıllık Analiz, 2018.

27. Yapicioglu H, Satar M, Ozcan K, Narli N, Ozlu F, Sertdemir Y, et al. A 6-year prospective surveillance of healthcare-associated infections in a neonatal intensive care unit from southern part of Turkey. J Paediatr Child Health 2010;46:337-42.

28. Naz H, Özgüneş I, Tekin N, Alpat Nayman S, Erben N, Akşit A, et al. Nosocomial infections and risk factors in neonatal intensive care unit. Turkiye Klin J Med Sci 2011;31:335-40.

29. Hacımustafaoğlu M, Çelebi S, Köksal N, Kavurt S, Özkan H, Çetinkaya M, et al. Nosocomial infections in neonatology clinic and neonatal intensive care unit. Turk Arch Pediatr 2011;46:3027.

30. Parlak E, Kahveci H, Köksal Alay H. Yenidoğan yoğun bakım Ünitesindeki hastane enfeksiyonlar1. J Curr Pediatr 2014;1:1-8.

31. Kılıç A, Atasay B. Yenidoğan yoğun bakım ünitesindeki nozokomiyal enfeksiyonların uluslararası standartlarla izleminin değerlendirilmesi, 2012.

32. Çağan E, Soysal A, Bakır M, Özek E. Yenidoğan yoğunbakım ünitelerinde sağlık hizmeti ilişkili kan akım enfeksiyonlarının 
prevalansı; ilk ulusal nokta prevalans çalışmasının sonuçları. Cukurova Med J. 2015;40:119-28.

33. Karabay M, Kaya G, Güçlü E, Öğütlü A, Karabay O, Caner İ. Yenidoğan yoğun bakım ünitesinde gelişen sağlık bakım ilişkili enfeksiyonlar: son 6 yılın değerlendirilmesi. Turkish J Pediatr Dis $2021 ; 15: 87-92$.

34. CDC Hospital acquired infections 2015 Current Descriptions http:/www.cdc.gov/nhsn/PDFs/ pscManual/15LocationsDescriptionscurrent.pdf 10.11.2020 'de ulaşılmıştır. 2015.

35. T.C. Sağlık Bakanlığı. Ulusal Sağlık Hizmeti İlişkili Enfeksiyonlar Sürveyans Rehberi, 2017.
36. Dellinger EP. Prevention of Hospital-Acquired Infections. Surg Infect (Larchmt) 2016;17:422-6.

37. Magill SS, O'Leary E, Janelle SJ, Thompson DL, Dumyati G, Nadle J, et al. Changes in prevalence of health care-associated infections in U.S. Hospitals. N Engl J Med 2018;379:1732-44.

38. Oruç Y, Yaşar N, Kara A, Düzgöl M, Çalkavur Ş, Bayram N, ve ark. Bir eğitim ve araştırma hastanesinde cdc 2014 sağlık hizmeti ile ilişkili enfeksiyon tanı kriterleri ile 2010 yılı türkiye hastane enfeksiyonlanı sürveyans rehberindeki tanı kriterlerinin karşılaştırılması. J Pediatr Inf 2016;10:6-9. 